\title{
ANAESTHESIA FOR THE SURGICAL CORRECTION OF CONGENITAL HEART DISEASE
}

\author{
CODE SMITH, M.D., B.SC. (MED.)*
}

DuRING the past ten years operative procedures for the amelioration and cure of congenital heart defects have become increasingly common and at the same tume more complex. This situation has stimulated, and to a large extent been made possible by, an increasing interest on the part of anaesthetists in cardiovascular physiology and pathology. While many anaesthetic techniques using a variety of agents have been devised, only those methods in current use at the Hospital for Sick Chlldren, Toronto, will be presented, together with a few observations regarding the more frequent complications and their treatment. An experience of over 450 cases during the past six years provides the background for this report (1).

Any anaesthetic technıque for cardiac cases must meet certain requirements. During operation, the adminstration of adequate oxygen and particularly the efficient elimmation of carbon dioxsde are of prime importance. The operative field must be maintained as nearly motionless as possible during the delicate surgical manoeuvres. Reflex activity, both respiratory ("bucking") and cardiovascular (arrhythmias, bradycardia, and arrest), must be depressed. Adequate means for the treatment of complications should be at hand. These include replacement solutions, various drugs, and an electrical defibrillator.

In addition, it is essential that the anaesthetist be familiar with the cardiac pathology of each patient, the type and degree of the deranged physiology and the contemplated operative procedure. The differential diagnosis, and the possibility of encountering, at operation, previously undetected anomalies necessitatıng changes in procedure, should be thoroughly understood before commencing the case. All cases posted for operation at this hospital are presented at weekly rounds and discussed by the cardiologist, surgeon, and anaesthetist before the decision to operate is made.

\section{Preoperative Medication}

Patients in failure receive one of the digitalis preparations for several days before operation.

Children rarely require a sedative on the evening before operation, but in the older child a moderate dose of seconal is occasionally employed.

Untıl recently a combination of a belladonna alkaloid with a naroctic administered intramuscularly 45 minutes before operation was used routinely. Atropine was employed in most cases. While scopolamine has the advantage of inducing a degree of amnesia, it has the disadvantage of increasing vagal tone as a result of its central action. This has resulted in an increase in the frequency of reflex cardiac arrhythmias which have required the intravenous admiristra-

*Hospital for Sick Children, Toronto, Canada. 
tion of atropine for their abolition. Both morphine sulphate, $1 \mathrm{mg}$. $/ 10 \mathrm{lb}$. and demerol, $8 \mathrm{mg}$. $/ 10 \mathrm{lb}$. have proven satisfactory. The latter has the advantage of being vagolytic in contrast with morphine which increases vagal tone.

Recently, premedication with a combination of chlorpromazine, promethazine $\mathrm{HCl}$, and demerol has given satisfactory results. Three techniques have been tried. Initially, the intramuscular injection of Laborit and Huguenard's (2) mixture num zer one (M1) was found to produce marked variations in the degree of sedation (Table I). The intravenous administration of this mixture

TABLE I

Mixture Number One (M1)

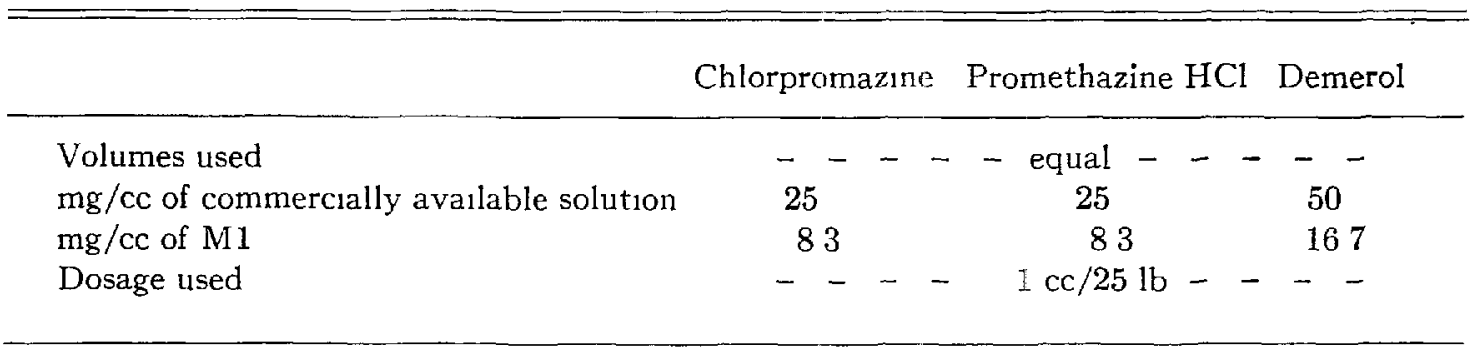

during the hour before operation produced a disturbing degree of tachycardia in a second group of cases. The present routine provides uniform sedation without undesirable side effects. Chlorpromazine and promethazine $\mathrm{HCl}$ are both given in doses of $1 \mathrm{mg} . / 3 \mathrm{lb}$. either orally or intramuscularly (depending on the size of the child) at 6 P.M. on the evening before operation and again at midnight. The dose is repeated at 6 A.M. the morning of operation and is followed by an intramuscular injection of atropine 45 minutes before operation (Table II). A variable degree of sedation is present when the child reaches the

TABLE II

Dosage of Atropine Sulphate

\begin{tabular}{ll}
\hline $10 \mathrm{lb}$ and under & gr $1 / 400$ \\
$10-20 \mathrm{lb}$ & gr $1 / 300$ \\
$20-40 \mathrm{lb}$ & gr $1 / 200$ \\
$40-80 \mathrm{lb}$ & gr $1 / 150$ \\
$80 \mathrm{lb}$ and over & gr. $1 / 100$
\end{tabular}

operatıng floor, and this is augmented by giving small fractional doses of M1 intravenously until the point is reached at which the patient can still be roused but immediately falls asleep if not disturbed.

\section{Induction and MatNTENANCE}

Anaesthesia is induced in all cases with sodium pentothal given intravenously. The injection is made quite slowly until about two "sleep doses" of the drug have been administered, and oxygen is given immediately following loss of 
consciousness. Whule a slight fall in blood pressure usually occurs at this time, frank cardiovascular collapse following sodium pen othal has not occurred. Immediately following the barbiturate, an injection o: decamethonium, $\mathbb{l l} \mathrm{mg} . /$ $50 \mathrm{lb}$., plus succinylcholine, $1 \mathrm{mg} . / 3 \mathrm{lb}$., is given and hyperventilation with oxygen carried on until apnoea supervenes. The trachea and larynx of the older children are then sprayed with cyclaine 5 per cent. Intubation is performed using the largest uncuffed portex tube that can be passed without trauma to the larynx An endo-oesophageal stethoscope is introduced and placed for optimum auscultation of heart sounds (3). Continuous auscultation of cardiac and respiratory sounds is cacried on throughout the operation.

Anaesthesia is maintained by a combination of non-exolosive agents. Nitrous oxide and oxygen are administered throughout, the pro sortions depending on the degree of cyanosis and general debility of the patient. Small amounts of sodium pentothal are occasionally added, but the totsl dose rarely exceeds $4 \mathrm{mg} / \mathrm{lb}$. When the expected duration of anaesthesia is greater than $1 \%$ ho irs an additional dose of decamethonium is administered about one hour follow.ng induction. The only other agent used is succinylcholine in small doses just sufficient to mantain apnoea. The indication for additional succinylcholine is etther the appearance of slight regular contractions of the diaphragm or increased resistance to manual inflation of the chest in spite of a free airway. Hyperventilation by controlled respiration is maintained at a point just short of interfering with the surgical procedure, and is interrupted each time a precise manoeuvre such as incising a vessel, placing a suture, or adjusting a clamp is made.

The present system appears to offer some advantages. Premedication with M1 reduces the amount of anaesthetic agent required, provides a basis for minimal anaesthesia and rapid return of consciousness, and results in a quiet, co-operative patient free from vomiting and requiring little narcotic for the control of postoperative pain. The non-explosive technique permits the use of various electrical apparatuses (electrocardiograph, oximeter, and hypothermia pump) near the head of the table and gas machine. The maintenance of apnoea with succinylcholine provides easy inflation of the contralateral lung with moderate degrees of positive pressure, a completely motionless field during the more exacting parts of the operation, and at the same time a rapid recovery of adequate respiratory exchange before the patient leaves the table.

\section{Complicattons and Treatment}

The commonest serious complication during cardiac surgery is a more or less rapid failure in the force of cardiac contraction. This is shown by a dilating weakly beating heart, diminished peripheral pulse, fall in blood pressure, and muffling of the heart sounds. Pupillary dilatation indicates the presence of cerebral hypoxia. Cardiac failure is usually accompanied by a degree of bradycardia and may be secondary to it. Whether the primary cause is reflex vagal slowing or myocardial asphyxia is of little import since in either case progression to cardiac arrest may occur, and treatment should be directed toward both etiologic factors. Operative manipulation should be suspended, and the lungs 
adminstration of large volumes of blood or plasma may in themselves depress cardiac activity as a result of infusing relatively large amounts of potassium ion. The injection of 10 per cent calcium chloride in $1 \mathrm{cc}$. increments to any rapidly running transfusion prevents this undesirable complication of treatment.

Acute pulmonary oedena may occur in a variety of conditions. Mechanical blocking of the small bronchioles by innumerable small bubbles, rather than the amount of fluid in the tracheobronchial tree, interferes with pulmonary ventılation. Passing the anaesthetic gases through a detergent such as ethanol in the ether chamber reduces the surface tension of these bubbles which clisintegrate, leaving a thin bloody flud which can be readily aspirated. The degree of positive pressure used during the inspiratory phase should be increased.

The sudden onset of deep inspiratory gasps is evidence of hypoxia stımulation of the carotid body chemoreceptors, and not of recovery from relaxants. This grave omen can occur even in the presence of complete relaxation and apnoea resulting from hyperventilation and the use of succinylcholine.

Dilatation of the pupls has already been mentioned as a sign of cerebral hypoxıa The persistence of dilatation despite efficient massage and the presence of a penpheral pulse is almost without exception prognostic of a fatal outcome.

Following ligation of a patent ductus the blood pressure rises sharply and there is a marked decrease in pulse pressure. The latter may be of such magnitude that a peripheral pulse is almost impossible to find, and undue alarm may be expenenced by the anaesthetist unless the blood pressure is taken by auscultation

A second benign situation which may be mistakenly considered serious is the presence of a large pericardia] effusion This may mask the true myocardial action beneath, producing the appearance of very feeble contractions. The presence of an adequate blood pressure and brisk heart sounds are reassuring, and the removal of the pericardial effusion by the surgeon permits constant observation of myocardial activity and cardiac size.

\section{HyPoTHERMiC ANAESTHESTA}

The reduction of metabolisin and hence oxygen requirement by physical cooling of the body is now being used in both cardiovascular and intracranial surgery A temperature of about $28^{\circ} \mathrm{C}$ is necessary for those procedures in which the enture circulation must be stopped for several minutes. As an adjunct in the surgery of less complicated cases, temperatures of 30 to $33^{\circ} \mathrm{C}$. decrease oxygen requirements and provide an increased margin of safety for the patient. Temperatures in this range are now being used routnely for all cyanotic and poor-risk patients

Infants are cooled by total immersion in a bath of cold tap water, and larger patients by wrapping in a mattress through which a refrigerant solution is crrculated

The routme system of premedication and anaesthesia described above is used. The inclusion of chlorpromazine in the premedication effectively prevents shivering during the cooling process, and the injection of $1 \mathrm{mg} / 5 \mathrm{lb}$ of this agent in refractory cases accelerates the rate of cooling. Sodium pentothal is not repeated 
following the induction dose, since its rate of elimination is decreased with decreased tissue metabolism.

At temperatures below $28^{\circ} \mathrm{C}$. the likelihood of spontaneous ventricular fibrilJation increases although it has been suggested by Bigelow (4) that the production of an alkalosis by hyperventilation may prevent this complication even at these temperatures. Electrical defibrillation of the cold heart is much more dufficult than defibrllation at normal body temperature. Warming the heart by filling the chest with warm saline may faclltate defibrillation. Intracordial prostigmine $0.05 \mathrm{cc}$. of the 1:4000 solution per $\mathrm{Kg}$, has been used in one refractory case with subsequent successful electrical defibrillation (5).

\section{Extracorporeal Heart-Lung Preparation}

The correction of some intracardiac anomalies requires an open heart for periods of 15 to 20 minutes. In such cases the beart and lungs are completely by-passed by removing blood from the venae cavae, oxygenating it in enther a mechanical or a biological lung, and pumping it back into the arch of the aorta. The anaesthetic management of these cases is again fundamentally the same as that for the more routine procedures In order to mantain the apnoeic state during the by-pass, a small dose of decannethonium is given several minutes before the extracorporeal circuit is turned on.

If there is evidence of increased bronchial circulation to the lungs gentle inflation of the patient's lungs with oxygen during this period may result in further oxygenation of the crrculating blood and the removal of some carbon dioxide. The problem of carbon dioxide elimination from the artificial lung should be appreciated and measures taken to reduce the mechanical dead space of the oxygenating system when a biological lung is used.

\section{SUMMARY}

A technique of anaesthesia for the correction of congenital heart defects is described. Premedication with chlorpromazine, promethazine $\mathrm{HCl}$, and demerol is followed by induction with sodium pentothal and maintenance of anaesthesia with nutrous oxide, oxygen, and the depolarizing relaxants A moderate degree of hypothermia is recommended for all cyanotic and deblitated patients. The more common complications are described, and reliance on calcrum chloride and atropine in their treatment is emphasized.

\section{RÉsumét}

L'auteur décrit une technıque d'anesthésie dans la correctıon des maladies congénitales du cœur Comme médication pré-opératoire, on donne du promethazıne et du chlorpromazıne la veille de l'opération qu'on fait suivre d'un mélange de prométhazıne, chlorpromazine et péthidine dans l'heure précédant l'opération L'induction se fart au Pentothal sodique. On intube après injection de decamethonuum et de succinylcholine L'anésthesie se poursuit au protoxyde d'azote, oxygen et de petites doses intermittentes de succinylcholine. On maintient une hyperventilation tout au long $d \cdot$. l'mtervention avec respiration controllée durant les manipulations du cœur ou des vaisseaux. 
Une hypothermie modérée est recommandee comme adjuvant dans les cas avec cyanose. Des températures aussi basses que $28^{\circ} \mathrm{C}$. sont nécessaires quand laction de pompe du coeur doit être arrêtée pour de courtes périodes.

La circulation doit être maintenue au moyen d'un extracornoréal dans les cas qui demandent un arrêt de la fonction cardiac pour de plus longues périodes.

La complication sérieuse habituelle au cours de la chirurgie est diminution progressive de l'action cardiaque allant parfois jusqu'à l'arrêt. La prophylaxie et le traitement de cette condition, soulignant l'emploie du chlorure de calcium et de l'atropine, est décrite.

\section{REFERENCES}

1. Mustard, W. T. C.M A J 72: 740-744 (1955).

2 Laborit, H \& Huguenard, P. Presse méd. 60-1455-1456 (1952).

3. SмтTH, C Anesthesiology, 15: 566 (1954).

4 Bigelow, W. G. Personal communication.

5 Prevedel, A. E, Montgomery, V. \& Swan, H. Proc. Soc. Exper. Biol. \& Med. 85: 596-597 (1954). 